\title{
GRAPHENE - GOOD NEWS FOR THE SCIENCE AND TECHNOLOGY OF THE 21ST CENTURY
}

\section{Sergey P. Gubin}

Kurnakov Institute of General and Inorganic Chemistry, Russian Academy of Sciences, http://www.igic.ras.ru 31, Leninsky prosp., 117991 Moscow, Russian Federation

gubin@igic.ras.ru

Abstract. The text of the speech, closes the first Russian conference on graphene "Graphene - a molecule and 2D-crystal", held in September 2015 in Akademgorodok, Novosibirsk (Russia) is presented. The assessment of the place of graphene in addressing contemporary issues of scientific and technical progress is presented. It presents the criteria that deny the so-called "Moore's Law" grounds for the application. The assumption of graphene as a single at the moment, post-silicon material for electronics is suggested. It is shown that the reality of the creation of biochips based on graphene.

Keywords: technological order, graphene, completely carbon nanoelectronics, biochips

PACS: 51.05.ue

Bibliography - 4 references

Received 25.11.2015

RENSIT, 2015, 7(2):131-134

DOI: $10.17725 /$ rensit.2015.07.131

\section{ConTENTS}

1. SiXth technological ORder (131)

2. THE GOOD NEWS FOR THE SCIENCE AND TECHNOLOGY OF THE 21sT CENTURY (132)

3. "LAW" MOORE AND POST-SILICON ELECTRONICS (132)

4. Artificial intelligence (133)

5. Conclusion (134)

REFERENCES (134)

\section{SIXTH TECHNOLOGICAL ORDER}

One of the most common paradigm for the global economics - cyclical its development and associated with its cycles so-called technological orders - a set of breakthrough technologies that form the new sectors of the economics. In the studies of the dynamics of science and technology progress formed an idea about six technological orders, which take place in development of this progress. The first order is dated by the 18th century with its first industrial revolution in the textile industry, second order is the era of steam engines of the 19th century, which converted shipping, coal mining, and created railways; third technological way with its second industrial revolution at the end of 19 th century is the era of steel; the fourth order is the internal combustion engines, wired telephone, automobile and aircraft construction, petrochemicals up to the $70 \mathrm{~s}$ of the 20th century; the fifth order of the 70 s of the 20 th - the early years of the 21 st century with its scientific and technological revolution the era of computers and telecommunications, biotechnology, new forms energy and materials, space and communications. Finally, the sixth technological order adopted to date the beginning of the 10-ies of our century and associated with nanotechnology and with convergence of nano, bio, info and cognitive technologies [1]. And the key here is, in my opinion, graphene and graphene-like materials. Sixth technological order is a century of carbon.

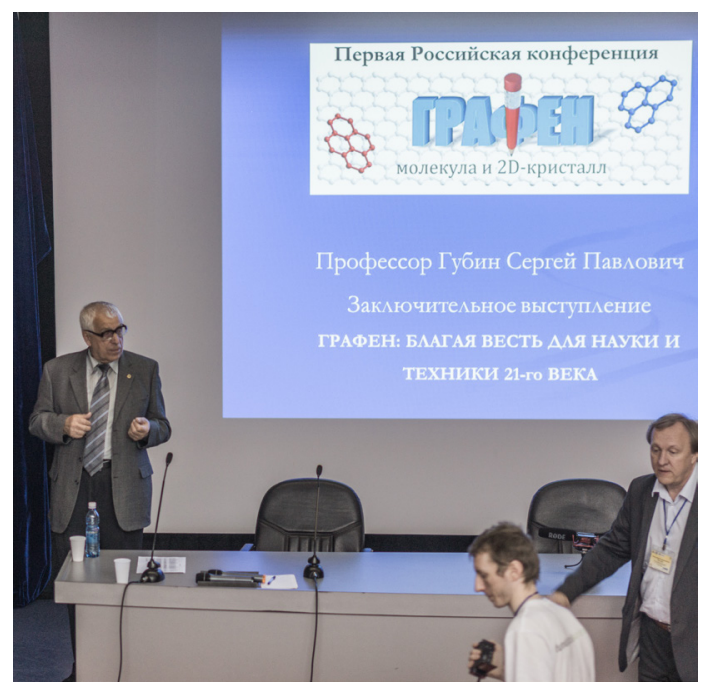

Fig. 1. Closing remarks at the conference. 


\section{THE GOOD NEWS FOR THE SCIENCE AND TECHNOLOGY OF THE 21ST CENTURY}

Century of carbon surely come. The question is only: as much as possible now? And is there any hope?

We are not the first and not the last we ask such a question. It casts the following analogy. From biblical mythology is well known that after the Flood, Noah, the old Noah, who was 600-something years old, collected in his ark pair of every creature, asked the same question [2]. I give here (Fig. 2) illustration French artist Gustave Dore, who lived only 51 years, has created more than 30,000 prints and drawings on biblical themes, depicting all the biblical legend. From my grandfather I still have an old bible huge thickness, where every two pages are illustrations Doré, and yet not knowing how to read, I leafed through with his grandmother this Bible and in head were postponed these biblical art images. So Noah, to know what to do next: water is gone, the Ark aground near Mount Ararat, but whether there is life, there is whether the conditions for life, whether it is possible to live on, is there any hope - he releases a dove. The dove flew, for some time flew, and finally flew back, holding in its beak a sprig of green

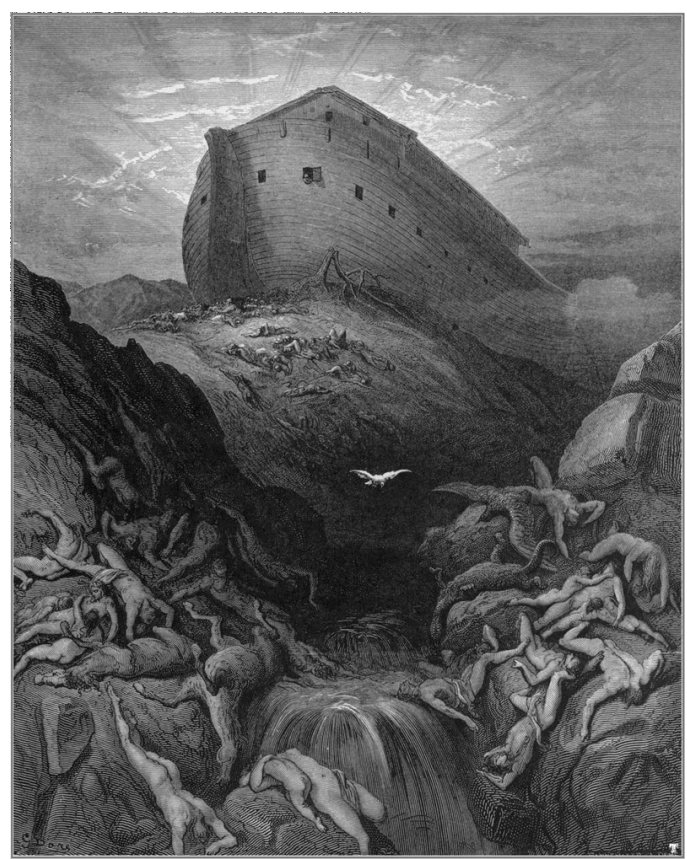

Fig. 2. Noah's Ark, Gustave Dore, 1864.

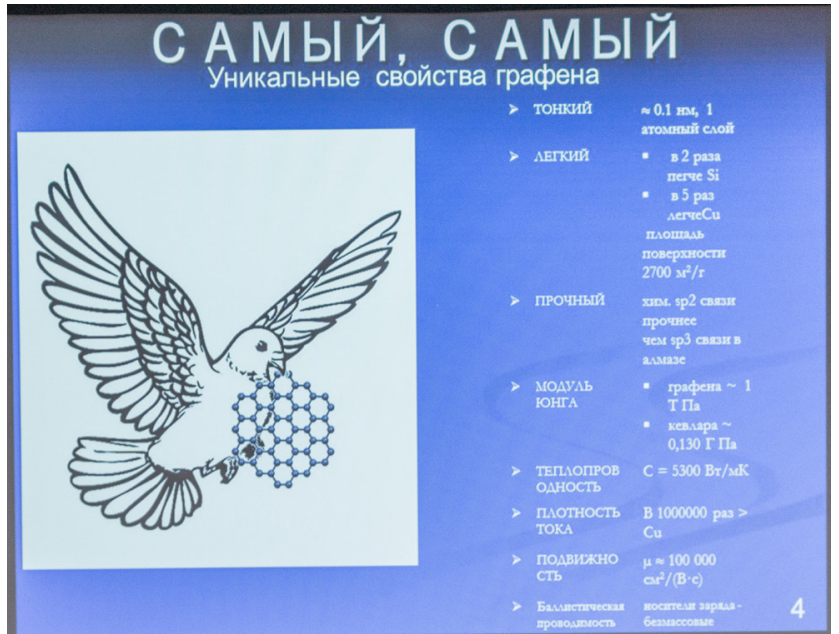

Fig. 3. The good news for the science and technology of the 21st century.

olives. That was the good news of life outside the ark. And now (Fig. 3) methinks that graphene is just such the good news.

\section{3. "LAW" MOORE AND POST-SILICON ELECTRONICS}

Through my many different literature, information, data passes, and I shared it all into two unequal parts. The first part briefly called "deadlocks" - that managed to be resolved or will be a success with using graphene. The second - "Surprises", ie then, that it was impossible to suggest, questions, that in no way it was impossible to ask some time ago. And once opened graphene and its properties were found, these surprises straight away showered as from the horn of plenty.

If we talk about deadlocks, then of course the most important is a dead end, an information, a dead end, associated with the non-realization of the individual elements. Already more than a decade we are disturbed at some affirmation, which we incorrectly called Moore's law [3]. No it is not a law, it's just a rule of thumb, man put three points on the same straight line, and went on to extrapolate it over time (Fig. 4). Here, in fact, there is no especial law. This so-called Moore's law is not respected and will not be complied with, when we come to dimensions smaller than $20 \mathrm{~nm}$.

The fact is that those professionals working in the field of physics and chemistry of 


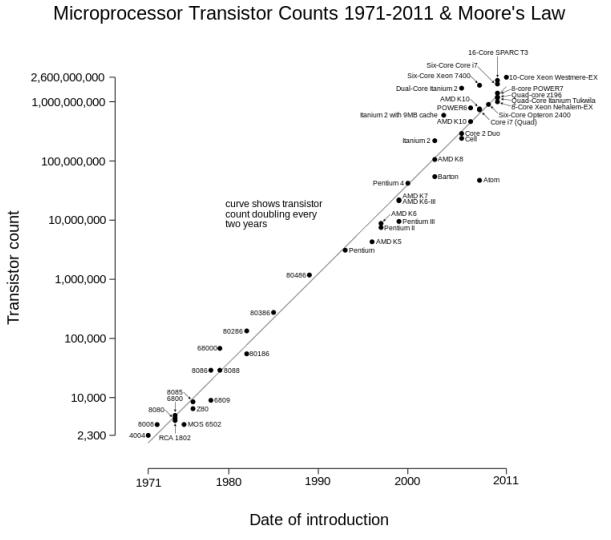

Fig. 4. Dependence of the number of transistors on a processor from time to time. The vertical axis - a logarithmic scale, that is, the straight line corresponds to exponential low: the number of transistors doubles roughly every 2 years [3].

nanoparticles - and this trend is quite intensively developed here years 20-25-30, it is developing and now - we very clearly understand and know that at sizes of particle of $20 \mathrm{~nm}$ essentially, fundamentally are changed many physicochemical parameters and conformities. Well, for example, at gold nanoparticles of $10 \mathrm{~nm}$ appears a bandgap. Forgive me, it is a metal, which has a well-defined band gap. And vice versa, bandgap of nanoparticles of silicon increases by 3.5 times while reducing the particle size up to 5-6 $\mathrm{nm}$.

Melting point such particles, of metallic for example, which are used in metal conductors, in contacts, which are present in very large electronic circuits, chips, etc. etc. - their melting temperature sharply falls, when you start to reduce them up to the nanoscale, up to $20 \mathrm{~nm}$ and less.

At our conference Sergey V. Tkachev from AkKoLab (VNIIAlmaz, Moscow) spoke about those stripes, that we make from silver nanoparticles. So here, in these strips the silver melts at $100-120^{\circ} \mathrm{C}$, whereas the melting point of silver is much higher. Gold has a melting point $1300^{\circ} \mathrm{C}$, its nanoparticles melts below $400^{\circ} \mathrm{C}$ [4], etc.

Since in today's integrated circuits with there is a large number of elements and they located very close together, then here arise high temperatures and, accordingly, produced a large amount of heat. Accordingly, there is dislodging of contacts, they cease to have the morphology, which them is given, which is drawn on most circuits, etc. Crisp edges no longer exist. And what does it mean? This means that they begin to merge, become thin up to the monolayer, and you lose on contacts a lots of charge and everything else. And solve this problem directly - segue to sizes smaller than $20 \mathrm{~nm}$, at existing planar technology, my deep conviction, will not succeed.

We must look for new ways. But new ways you can only search on other materials. Once is formulated question, it must be the answer. The question is formulated as follows: what will happen after the silicon electronics? Clearly, this will not gallium nitride, not gallium arsenide, not diamond films, although each of these materials has its interesting advantages, have interesting properties, etc., etc. But this is not the solution. Only graphene and its variants, various derivatives of graphene will allow us, seems, to resolve this issue.

\section{ARTIFICIAL INTELLIGENCE}

It is also a problem of the sixth technological order. I am far from here to talk about information-, neuroand any other part of this problem. I am again interested in the material side of the case. The first and most real, what is being done and can be done - to create a symbiosis between man and computer - interface the human brain-computer. But how to do that? To do this into a living organism is to be implanted a chip.

The first problem here - compatibility issue, she now is very serious. Those silicon chips that are made today, they are numerous for different tasks, for different purposes, they are, first, painful when injected into the human body, and secondly, there is a reaction of rejection. Why? The body, its cell systems have the property to reject any extraneous, alien objects, which try to squeeze, to enter into their structure.

From this standpoint, graphene - a material that we can modify before gaining them the properties intrinsic of living tissues and it is not a fantasy. In

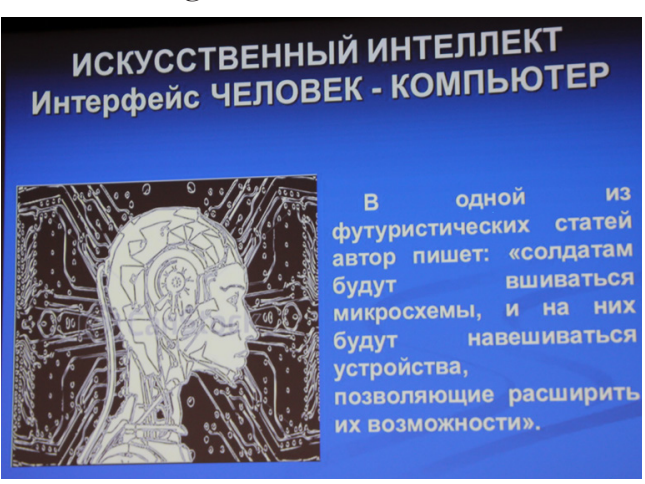

Fig. 5. The interface "man-computer". 


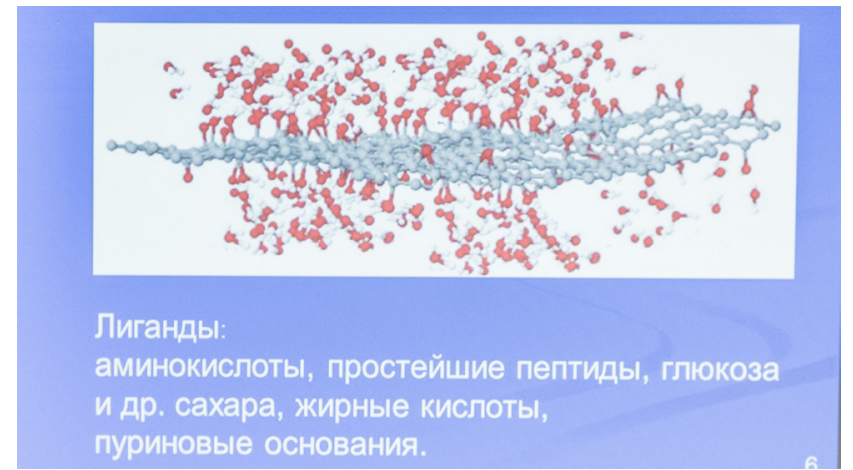

Fig. 6. The graphene flake surrounded by ligands.

Fig. 6 is listed, that already performed on certain examples. You can take a flake of graphene and cover it with those ligands, which for biological systems, for cells are not foreign, they are close to them and on the composition, and function. Herewith, of course, some electrical and other properties of the graphene may be changed. But we can control it, we know what we are doing, we can take here this amino acid to get desired values, we can take another amino acid, or protein fragment, and to receive the other characteristics. It is manageable process.

Nothing like with a silicon wafer can not be made, in principle. You can't bind to it all these groups chemically, and hence it is - a deadlock. With graphene this problem can be solved.

But this does not mean that today we have the final decision. This is just the direction that I think is a real direction. And there will be many difficulties, many things still need to do here.

\section{CONCLUSION}

As the Good News brings salvation, the hope of life, strength to endure all the hardships of her, so graphene gives humanity in the early 21 st century solution to the key problems of electronics - one of the basic elements of a modern economics. And our work with graphene gives us the consciousness of your stay at the peak of modern science.

\section{REFERENCE}

1. L'vov DS, Glaz'ev SYu. Theoretical and applied aspects of NTP. Economics and Mathematical Methods. 1986, 5:793-804.

2. Bible. Genesis 6:13-8:19. Moscow, Russian Bible Society Publ., 2011.

3. Moore GE. No Exponential is Forever: But "Forever" Can Be Delayed! International SolidState Circuits Conference (ISSCC), 2003.
4. Tkachev SV, Buslaeva EYu, Gubin SP. Graphene is produced by reduction of graphene oxide supercritical isopropanol. Abstracts of the First Russian conference "Graphene - a molecule and 2D-crystal", Novosibirsk, NIIC SB RAS Publ., 2015, p. 170. 